Oldenburg, F. J., Nilsson, E., Schmidt, T. J., \& Gubler, L. (2019). Tackling capacity fading in vanadium redox flow batteries with amphoteric polybenzimidazole/nafion bilayer membranes. Chemsuschem, 12(12), 2620-2627. https://doi.org/10.1002/cssc.201900546

WILEY-VCH

\title{
Tackling Capacity Fading in Vanadium Redox Flow Batteries with Amphoteric PBI/Nafion Bilayer Membranes
}

\author{
Fabio J. Oldenburg, ${ }^{[a]}$ Elisabeth Nilsson, ${ }^{[a]}$ Thomas J. Schmidt ${ }^{[a, b]}$ and Lorenz Gubler ${ }^{[a]}$
}

\begin{abstract}
Vanadium flow batteries are among the most promising technologies for stationary energy storage applications if their cost of storage can be further decreased. Capacity fading resulting from imbalanced vanadium crossover is a key operating cost component. We report a new approach to avoid this cost by balancing electrolyte transport with amphoteric bilayer Nafion $₫ /$ meta-polybenzimidazole membranes. Within this system, the anion- and cation exchange capacity can be tuned in straightforward manner via the thickness of the respective polymer layer to balance electrolyte transport for a given current density. At high current densities a net migrative flux of vanadium directed towards the positive side is observed due to the higher average charge of vanadium ions present at the negative side. The coulombic repulsion between the vanadium ions and the positive charges in the membrane counteracts this migrative transport and is able to reverse the direction of the net vanadium flux. For a technically relevant current density of $120 \mathrm{~mA} \mathrm{~cm}^{-2}$, a PBI thickness of 3-4 $\mu \mathrm{m}$ is required to balance the vanadium crossover and to minimize capacity fading.
\end{abstract}

\section{Introduction}

Vanadium redox flow batteries (VRFB) are among the technologies providing the lowest cost of stationary energy storage per installed capacity. [1] Their low levelized cost of storage (down to $120 \$ / \mathrm{MWh}$ ) results mainly from their large lifetime of $10,000+$ cycles. [2] To allow commercial viability of a wide range of applications, capital and operating expenditures must be reduced. The membrane is the key component to address this problem, primarily because it provides the largest direct cost reduction potential [3], and secondarily because it governs electrolyte transport processes that may result in electrolyte imbalance limiting the accessible capacity. Electrolyte imbalance originates from a net vanadium transport across the membrane yielding vanadium accumulation on one side and

[a] F.J. Oldenburg, E. Nilsson, T.J. Schmidt, Dr. L. Gubler (corresponding author) Electrochemistry Laboratory

Paul Scherrer Institut

Forschungsstr. 111, 5232 Villigen, Switzerland

E-mail: Lorenz.gubler@psi.ch

[b] Prof. Dr. T.J. Schmidt

Laboratory of Physical Chemistry

ETH Zürich

8093 Zurich, Switzerland

Supporting information for this article is given via a link at the end of the document. vanadium deficiency on the other electrolyte side.[4] The vanadium deficient side limits the capacity, which can be regenerated either with periodic remixing of the negative and positive electrolyte once the capacity reached a critical level or continuous reflow. [5-7] Increasing the membrane's barrier properties towards vanadium ions does only slow down this effect.[8-11] The cost of remixing for a $6 \mathrm{MWh}$ battery that looses $1.8 \%$ of its discharge capacity per cycle at $60 \%$ discharge capacity is estimated to be $>8 \$ \mathrm{MWh}^{-1}$, which translates to $350.000 \$$ over the expected lifetime of 20 years (see ESI for the detailed calculation). On the other side, continuous reflow translates into a continuous discharge causing an efficiency loss of up to $10 \%$ at low current densities. [12] Finding a way to effectively mitigate electrolyte imbalance and the resulting capacity fading thus is a key challenge towards reducing the levelized cost of storage of vanadium flow batteries. Electrolyte imbalance can be studied by measuring the flux of vanadium ions through the electrolyte membrane of the flow cell. The flux $J_{i}$ of an ionic species $i$ can be described with the Nernst-Planck equation including the transport modes diffusion and migration:

$$
J_{i}=-D_{i} \nabla c_{i}-z_{i} \mu_{i} F c_{i} \nabla \varphi
$$

with the diffusion coefficient $D_{i}$, the concentration $c_{i}$ (inside the membrane), the charge of the ion $z_{i}$, its mobility $\mu_{i}$, the Faraday constant $F$, and the potential $\varphi$. To relate the mobility $\mu_{i}$ to the diffusivity $D_{i}$, we recall the Nernst-Einstein equation

$$
D_{i}=R T \mu_{i}
$$

The potential gradient can be substituted using Ohm's law

$$
i=-\kappa \nabla \varphi
$$

with the membrane conductivity $\kappa$ and the more tangible current density $i$, resulting in equation 4 :

$$
J_{i}=-D_{i} \nabla c_{i}-\frac{z_{i} D_{i} F c_{i}}{\kappa R T} i
$$

The ionic flux $J_{i}$ in equation 4 describes the ion transport across the membrane. If the sum of vanadium transported towards the positive side $\left(\mathrm{V}^{2+}\right.$ and $\left.\mathrm{V}^{3+}\right)$ differs from the sum of vanadium transported towards the negative side $\left(\mathrm{VO}^{2+}, \mathrm{VO}_{2}{ }^{+}\right)$, a net vanadium flux across the membrane is observed yielding capacity fading. The direction of the net vanadium flux can be estimated by comparing the two ion specific coefficients, $D_{i}$ and $z_{i}$ in equation 4 of $\mathrm{V}^{2+}$ and $\mathrm{V}^{3+}$ with those of $\mathrm{VO}^{2+}$ and $\mathrm{VO}_{2}{ }^{+}$. Table 1 
lists these coefficients for all the vanadium ions as reported in different experimental studies for a cation exchange membrane (Nafion® N115). When comparing the diffusion coefficients $D_{i}$, which must be weighted by the ionic charge $z_{i}$, all 3 references suggest a higher flux for $\mathrm{V}^{2+}$ and $\mathrm{V}^{3+}$, which would result in a net vanadium flux towards the positive side.

Table 1. Nominal charges $\left(z_{i}\right)$ and experimental diffusion coefficients $\left(D_{i}\left[10^{-12} \cdot \mathrm{m}^{2} \mathrm{~s}^{-1}\right]\right)$ of $\mathrm{V}^{2+}, \mathrm{V}^{3+}, \mathrm{VO}^{2+}$ and $\mathrm{VO}_{2}{ }^{+}$.

\begin{tabular}{lcccc} 
& $z_{i}$ & $D_{i}[13]$ & $D_{i}[14]$ & $D_{i}[15]$ \\
\hline $\mathrm{V}^{2+}$ & 2 & 8.77 & 9.44 & 3.39 \\
$\mathrm{~V}^{3+}$ & 3 & 3.22 & 14.45 & 1.87 \\
$\mathrm{VO}^{2+}$ & 2 & 6.83 & 4.45 & 2.84 \\
$\mathrm{VO}_{2}{ }^{+}$ & 1 & 5.90 & 2.40 & 2.32 \\
\hline
\end{tabular}

Darling et al. modelled the net vanadium flux and analyzed the transport across a cation exchange membrane (Nafion $\otimes N 115$ ) of each vanadium ion at different current densities. A net vanadium flux directed towards the positive side was observed due to the higher average charge $z_{i}$ of vanadium ions present in the negative electrolyte. [16] This net migrative flux is in particular strongly pronounced at high current densities. As a result, $\mathrm{VO}^{2+}$ is accumulated in the positive electrolyte, since the crossing species $\left(\mathrm{V}^{2+}\right.$ or $\left.\mathrm{V}^{3+}\right)$ are chemically and electrochemically oxidized. The performance of the vanadium flow battery is hence limited due to vanadium depletion on the negative electrolyte side, causing capacity fading. If the membrane does not allow sufficient osmotic water transport to accompany the vanadium transport, asymmetric vanadium concentrations build up. A decreasing vanadium-ion concentration on the negative side enhances concentration overpotentials and reduces the voltaic efficiency, whereas an increasing concentration on the positive side accelerates irreversible V(V)-precipitation. Several approaches to tackle this problem have been introduced on the device level, including asymmetric electrolyte volumes $[17,18]$, asymmetric charge-discharge current densities [19] or constant and periodic electrolyte rebalancing $[5,20]$. In the case of microporous separators, asymmetric tank pressures [21] or an additional organic draw solute [22] were utilized to counteract imbalanced electrolyte fluxes. All of these symptom fighting approaches bring along other performance losses, add to the system operational complexity and increase the operating cost of the system. We have shown in previous work that the magnitude and direction of the net vanadium flux fundamentally depends on the type of membrane used. By balancing cation and anion exchange groups in an amphoteric ion exchange membrane, the net vanadium flux and the capacity fading were significantly reduced. [23] In this work we study the influence of cation and anion exchange functions in the membrane on the diffusive and migrative transport of the different vanadium ions. The results are presented in the context of previous theoretical studies and should guide vanadium flow battery developers to choose the membrane according to their application range in order to balance transport processes without loosing performance nor adding to the total cost of ownership. As a model system, a bilayer Nafion $\AA /$ metapolybenzimidazole ( $\mathrm{mPBI}$ ) membrane was chosen to allow simple tuning of the anion- and cation exchange properties of the hybrid material. Similar membranes have been widely studied in the context of improving the barrier property of the highly conductive Nafion $\AA$ membrane. [24-28] Ahn et al. recently reported a superior energy efficiency of $>90 \%$ when using a spray-coated Nafion $\circledast /$ poly[2,20-(2-benzimidazole- $p$-phenylene)-5,50-

bibenzimidazole] membrane. [29] This approach yielded also a significantly improved oxidative stability compared to pristine PBI, due to the shielding effect of the Nafion ${ }^{\circledR}$ layer.

\section{Results and Discussion}

\section{Tuning fixed ionic charges in bilayer membranes}

Amphoteric PBI/Nafion bilayer membranes were prepared by hotpressing a precast $\mathrm{PBI}-\mathrm{membrane}$ onto a commercially available Nafion ${ }^{\circledR}$ membrane of defined thickness (Nafion® NR212 with $54 \mu \mathrm{m}$ dry thickness). PBI was prepared at different thicknesses by casting a 10 weight $\%$ solution of meta-PBI in dimethylacetamide onto a glass plate (the detailed experimental conditions are provided in the ESI).

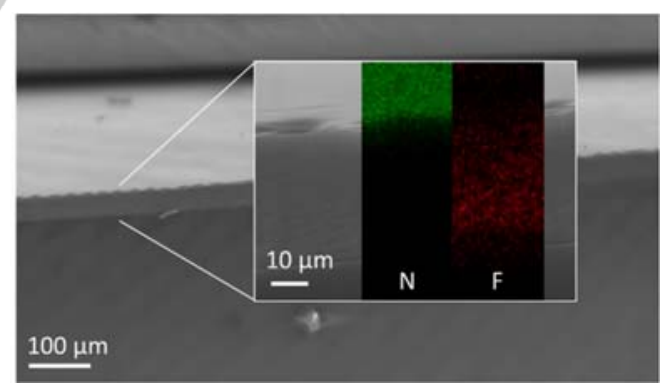

Figure 1. Cross-sectional analysis of a PBI/Nafion bilayer membrane with a PBI thickness of $4 \mu \mathrm{m}$. in gray: SEM image in colour: EDX elemental mapping of nitrogen (green) and fluor (red) (cf. ESI).

The cross-sectional analysis of the hot-pressed bilayer reveals a defined interface (Figure 1). In accordance to previous literature, the two films stay attached to each other even after extended operation in the test cell due to strong acid-base interaction of the two materials (cf. ESI, Figure S2). [29] The PBI layer thickness defines the content of benzimidazole moieties, which are protonated in the acidic vanadium electrolyte and act as fixed positive charges across the membrane, which can be expressed through the anion exchange capacity (AEC) of the bilayer film. 
The anion exchange capacity and cation exchange capacity (CEC) were determined by precipitation titration with $\mathrm{AgNO}_{3}$ and acid-base titration with $\mathrm{KOH}$, respectively. Figure 2 presents the share of $A E C$ with respect to the total ion exchange capacity for bilayer PBI/NR212 membranes with different PBI thicknesses.

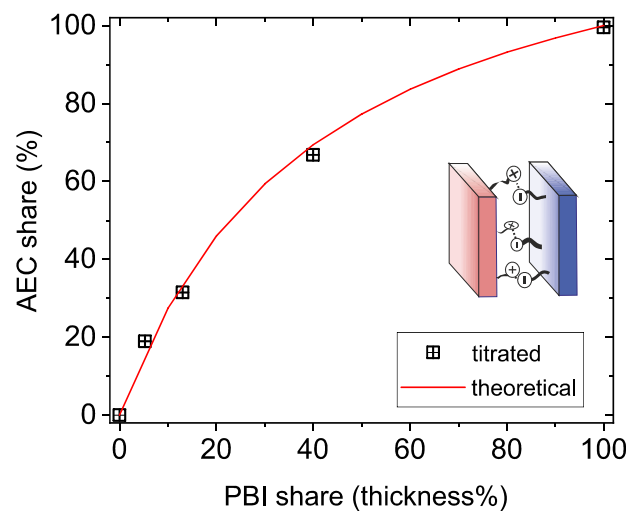

Figure 2. Share of anion exchange capacity in bilayer PBI/NR212 membranes with variating $\mathrm{PBI}$-thickness (cf. ESI).

The experimentally determined number of anion and cation exchange groups is in good agreement with the theoretically expected value (predicted from the CEC and AEC of pure NR212 and $\mathrm{PBI}$, respectively, cf. ESI, page 3). For amphoteric membranes in particular, this is only rarely observed: due to the strong ionic interaction of cation and anion exchange groups a loss of ion exchange capacity is typically reported for amphoteric ion exchange materials in the literature. $[10,30]$ In bilayer membrane architectures, the bulk of the cation and anion exchange groups is separated from each other, which allows to precisely adjust the ratio of fixed positive to negative charges.

\section{Ex situ diffusion experiments and membrane area resistance} Coating an anion-exchange layer with a defined content of fixed positive charges onto a Nafion $\AA$ membrane has three major effects on the vanadium flow battery performance: i) a barrier towards redox-active vanadium ions is introduced, yielding higher coulombic efficiency; ii) the net vanadium flux can be balanced resulting in less pronounced capacity fading and iii) the throughplane area resistance increases yielding lower voltage efficiencies. The thickness of the anion-exchange layer (in this case $\mathrm{PBI}$ ) must be optimized with a focus on all three performance indicators to have a net positive effect on the VRFB performance. To allow operation over a broad range of current densities, we target a membrane that is contributing with less than $0.5 \Omega \mathrm{cm}^{2}$ (corresponding to Nafion $\AA \mathrm{N} 117$ ) to the ohmic resistance of the cell. Figure 3 presents the area resistance of a cell assembled separately with Nafion ${ }^{\circledR}$ and free-standing PBI membranes at different thicknesses. The background resistance of the cell $(0 \mu \mathrm{m}$ membrane thickness) was determined using a porous separator (Treo-Pore $®$ PDA, $20 \mu \mathrm{m}$ thickness), which fits well to the linear extrapolation of the area resistance of $\mathrm{Nafion} \circledast$ and PBI. The background cell resistance of $0.4 \Omega \mathrm{cm}^{2}$ is related to the finite conductivity of the vanadium electrolyte, the carbon felt electrodes and contact resistances between the different cell components.

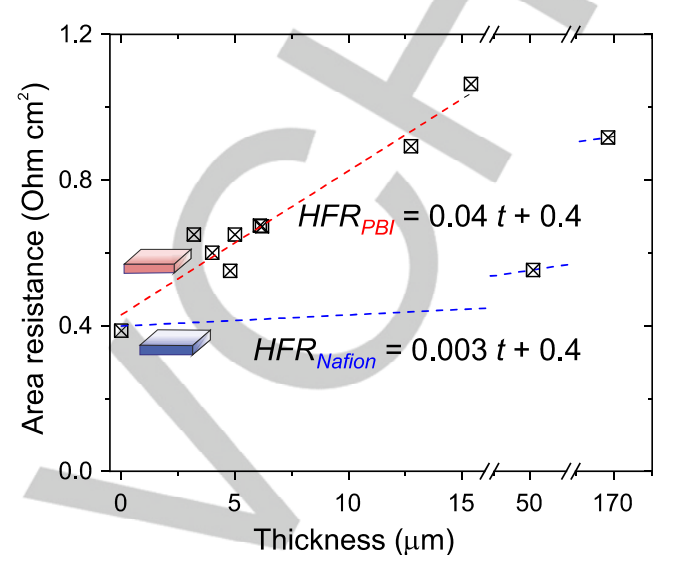

Figure 3. Through-plane area resistance obtained from electrochemical impedance spectroscopy on a cell assembled with Nafion ${ }^{\circ}$ and PBI membranes of different thicknesses $t$ and a vanadium electrolyte at $-50 \%$ state of charge (1.6 M V and 2.1 $\left.\mathrm{M} \mathrm{H}_{2} \mathrm{SO}_{4}\right)$. The intercept and the slope of the linear fit correspond to the background cell resistance, and the reciprocal throughplane conductivity, respectively.

The effect of the membrane's content of fixed positive charges on the net diffusion of vanadium ions across the membrane in the absence of an electric field was studied in home-made diffusion cells. To estimate the net vanadium flux across the membrane in the cell, diffusivities were determined separately for all oxidation states present in the all-vanadium redox flow battery. Figure 4 presents the diffusivity of each vanadium ion measured for different PBI/NR212 bilayers with varying PBI-thickness.

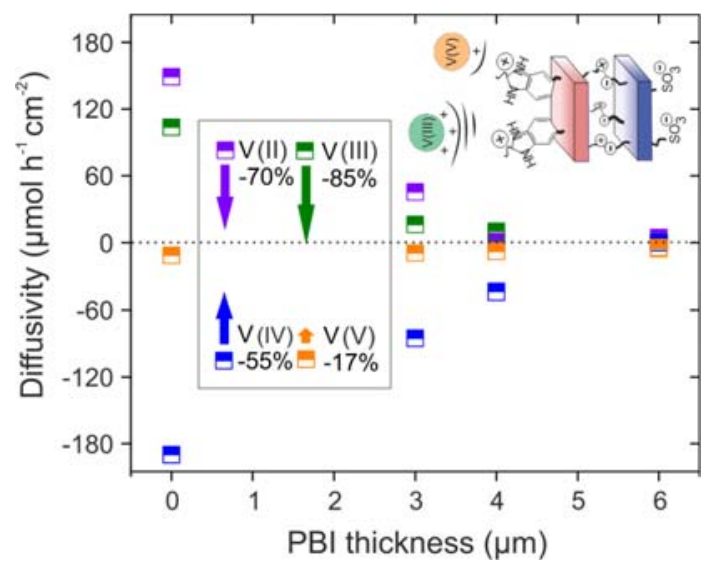

Figure 4. Diffusivity of $\mathrm{V}(\mathrm{II}), \mathrm{V}(\mathrm{III}), \mathrm{V}(\mathrm{IV})$ and $\mathrm{V}(\mathrm{V})$ determined in diffusion experiments across bilayer PBI/NR212-membranes with varying PBI-thickness. A negative or positive value indicates the transport is expected to be directed towards the negative and positive side, respectively. 
In the case of Nafion® NR212 $(0 \mu \mathrm{m} \mathrm{PBI}) \mathrm{V}(\mathrm{IV}), \mathrm{V}(\mathrm{II})$ and $\mathrm{V}(\mathrm{III})$ exhibit a much higher diffusivity compared to $\mathrm{V}(\mathrm{V})$, which is in accordance with the results reported by Luo et al. and which can be explained with the relatively large solvation shell of the ion. $[14,30]$ As a consequence, the net vanadium flux (sum of the transport of all vanadium ions) is expected to be directed towards the positive side for Nafion ${ }^{\circledR}$ NR212.

By adding a thin layer of $\mathrm{PBI}$, fixed positive charges are introduced onto the Nafion $®$ membrane, which repel the positively charged vanadium ions according to their charge $\left(z_{i}\right)$. Although the ionic concentration is above the Donnan exclusion limit, the diffusion coefficients are significantly affected and the diffusivity is decreasing with increasing charge of the outer solvation shell. For bilayer membranes with $3 \mu \mathrm{m}$ of $\mathrm{PBI}$ (representing a $20 \%$ share of $A E C)$, the diffusivities of $\mathrm{V}(\mathrm{II}), \mathrm{V}(\mathrm{III}), \mathrm{V}(\mathrm{IV})$ and $\mathrm{V}(\mathrm{V})$ decrease by $70 \%, 85 \%, 55 \%$ and $17 \%$, respectively, compared to the pristine NR212 membrane (cf. Figure 4). The difference of the effect on $\mathrm{V}(\mathrm{II})=\mathrm{V}^{2+}$ and $\mathrm{V}(\mathrm{IV})=\mathrm{VO}^{2+}$ (which have the same nominal charge) can be explained with the presence of counterions in the first solvation shell of $\mathrm{VO}^{2+}$, which reduces the effective charge of the ion. [31,32] Increasing the PBI layer thickness to $6 \mu \mathrm{m}$ decreases the transport further up to a point where vanadium crossover was not detectable anymore within the experimental time of two weeks. Thus a PBI-thickness of more than $6 \mu \mathrm{m}$ is not recommendable since the resistance would further increase without any benefits on vanadium transport. To discuss the net direction of vanadium flux in the cell without any contribution of the potential gradient (or influence of current density) one has to compare the sum of transport rate towards the positive side $\left(\mathrm{V}^{2+}\right.$ and $\left.\mathrm{V}^{3+}\right)$ and towards the negative side $\left(\mathrm{VO}^{2+}\right.$ and $\mathrm{VO}_{2}{ }^{+}$), cf. Figure 5 . The higher the number of fixed positive charges in the membrane, the more strongly the transport towards the positive side is supressed and the net flux is shifting towards the negative side (already at a PBI thickness below $3 \mu \mathrm{m}$ ). With a $\mathrm{PBI}$-layer exceeding a thickness of $4 \mu \mathrm{m}$, the transport of all vanadium ions is largely supressed.

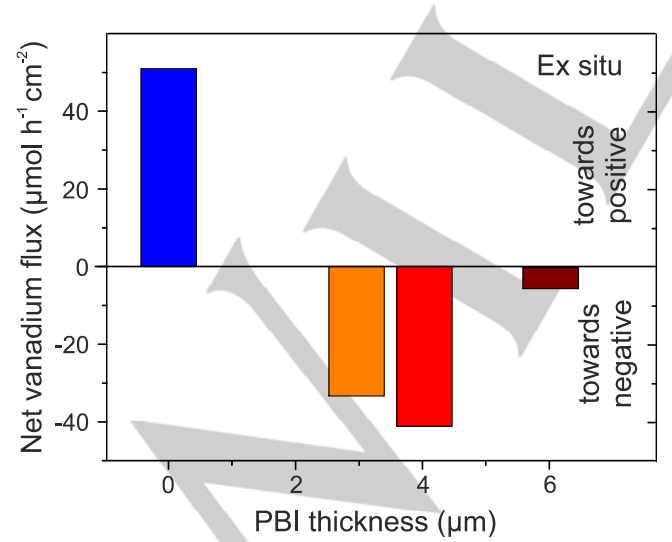

Figure 5. Expected net vanadium flux determined from the diffusivity of each ion across a NR212 membrane (cf. Figure 4) with varying thickness of the PBI layer. A positive flux corresponds to a transport directed towards the positive side, and vice versa.

\section{In situ transport at different current densities}

The transport of each vanadium ion across the membrane is driven by diffusion, migration and electroosmotic drag. $[4,33]$ The two latter modes are linearly depending on the current density, hence these terms are predominantly governing the transport at high current densities. According to the Stokes-Einstein relation, diffusion is correlated to the viscosity of the solvent and the Stokes-radius of the dissolved ion, whereas migrative and electroosmotic transport in addition scales with the effective charge of the dissolved ion. The diffusion coefficients used in previous studies were experimentally obtained in diffusion experiments with a constant concentration gradient over a Nafion $® N 117$ membrane using electrolyte with only one type of vanadium ion. In a real cell environment, however, this concentration gradient changes as a function of the state of charge and vanadium ions of all oxidation states are present in the membrane. The transport (and diffusion coefficients) across a membrane measured in situ appears significantly smaller. [23] Here, the net flux of vanadium across the membrane was determined by following the amount of vanadium in the fully discharged negative and positive electrolyte with redox titration over 50 charge discharge cycles (cf. ESI). From the varying total amount of vanadium present in the two electrolyte compartments, the net vanadium flux was determined. For all measurements, the first 20 cycles were used for conditioning and neglected in the analysis (cf. ESI). Figure 6 presents the net vanadium flux of $\mathrm{PBI} /$ Nafion ${ }^{\circledR}$ membranes with varying $\mathrm{PBI}$ thickness at different current densities. Already at $40 \mathrm{~mA} \mathrm{~cm}^{-2}$ this net flux is significantly shifted towards the positive side compared to the ex situ flux in the absence of a potential gradient. At $40 \mathrm{~mA} \mathrm{~cm}^{-2}$ a PBI-thickness of 3-4 $\mu \mathrm{m}$ would be required in order to balance the vanadium flux. With increasing current density the net flux is further shifted towards the positive side: at $120 \mathrm{~mA} \mathrm{~cm}^{-2}$ a PBI thickness of more than $4 \mu \mathrm{m}$ is required for cancelling net vanadium transport. Due to the high anion exchange capacity of protonated PBI (and the correlated high concentration of fixed positive charges), one micrometre of $\mathrm{PBI}$ has already a significant influence on vanadium transport. The experimental results confirm the theoretical findings by Darling et al. and the linear influence of the current density. However, when introducing an anion exchange layer, the contribution of anion exchange groups must be considered to obtain a complete picture of transport processes over time. Especially in the case of bilayer membranes the cation and anion exchange capacities offer a valuable degree of freedom to adjust and balance vanadium transport for a given current density. Under real operation conditions the current density is not constant, thus the membrane must be developed according to an average current density for a given application. 


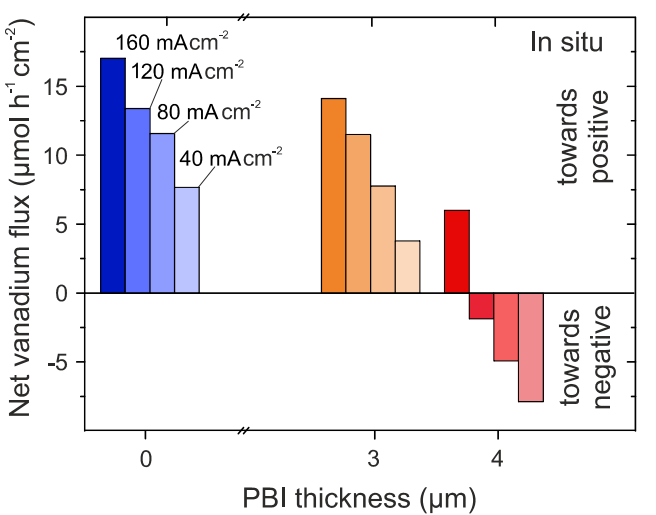

Figure 6. In situ net vanadium flux observed for $\mathrm{PBI} / \mathrm{Nafion}{ }^{\circledR}$ bilayer membranes with varying PBI thickness at different current densities. The flux was calculated from the difference in vanadium content in the positive and negative electrolyte between cycles 20 and 50 .

\section{Performance and influence on capacity fading} Imbalanced vanadium transport limits the performance in two ways: a net vanadium flux is continuously depleting the redox- active compound in one of the electrolytes resulting in capacity fading. This is a reversible loss of capacity, yet its rebalancing increases operation and maintenance complexity and limits the efficiency. [6] If the net vanadium flux furthermore results in a concentration decrease on one side, voltaic losses can result from concentration overpotentials. Side reactions, such as $\mathrm{H}_{2-}$ evolution, can cause further capacity loss due to the formation of asymmetric valences between the negative and positive electrolyte. [4,34] However, this was mitigated by limiting the operating cell voltage to $1.6 \mathrm{~V}$. Figure 7 presents the performance of a cell assembled with Nafion ${ }^{\circledR} \mathrm{NR} 212$, and two bilayer $\mathrm{PBI} / \mathrm{NR} 212$ membranes over 50 charge-discharge cycles at $160 \mathrm{~mA} \mathrm{~cm}^{-2}$. The coulombic efficiency is correlated to the membrane's vanadium-barrier properties and was observed to be stable over 50 cycles. A PBI thickness of $2 \mu \mathrm{m}$ is already sufficient to improve the coulombic efficiency up to almost $100 \%$. The voltaic efficiency was slightly decreasing for all tested membranes. This effect is attributed to the instability of heat-treated carbon feltelectrodes. [35] Especially at high current densities, the polarization resistance increases significantly over time lowering the voltaic efficiency (cf. ESI, page 4). However, the voltaic efficiency appears to be more stable in the case of bilayer

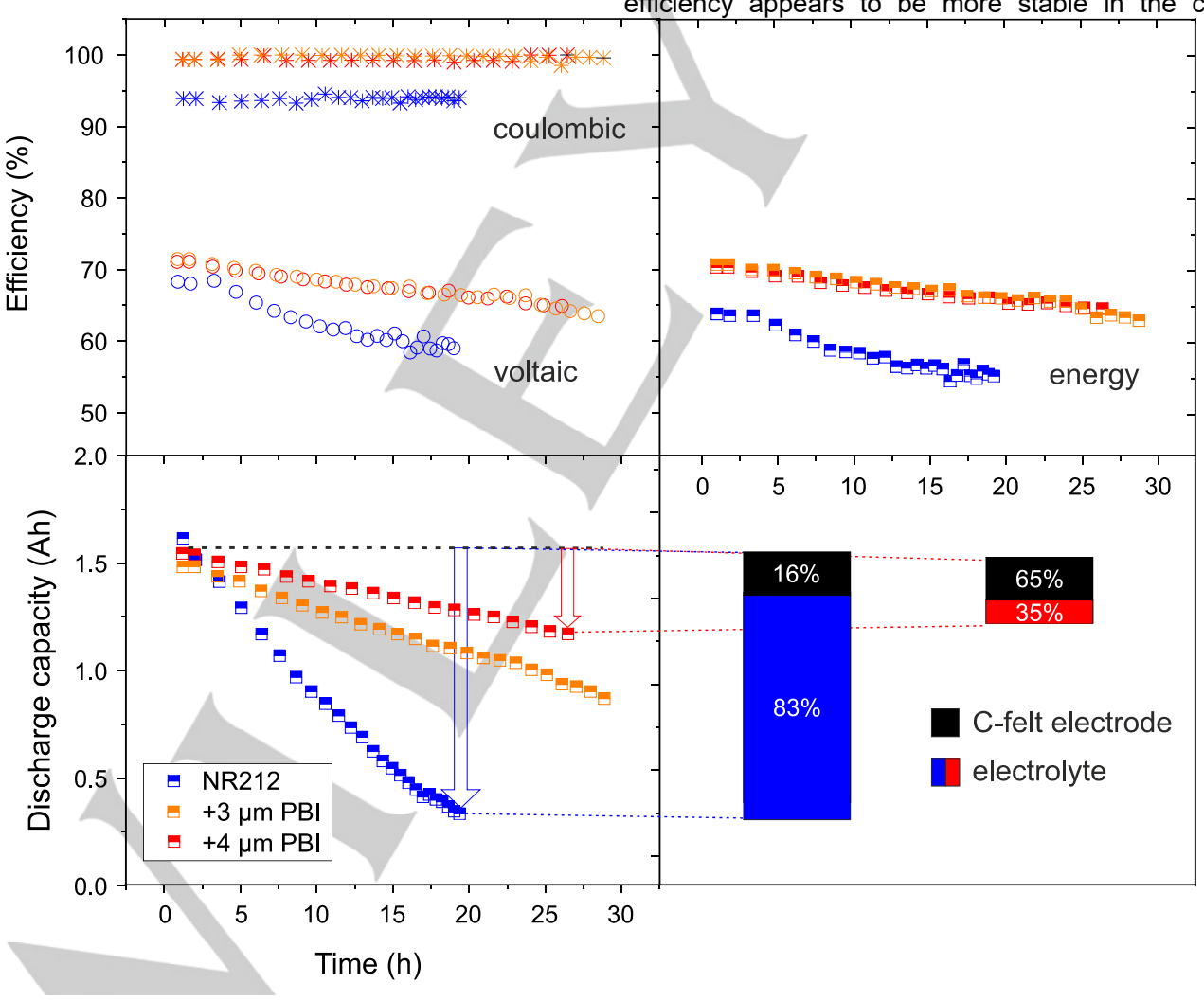

Figure 7. Cycling performance over 50 charge-discharge cycles of a redox-flow test cell assembled with PBI/Nafion® membranes with varying PBI thickness at $160 \mathrm{~mA} \mathrm{~cm}^{-2}$. Testing conditions: heat-treated SGL GFD4.6EA carbon felt electrodes at $30 \%$ compression, $60 \mathrm{~mL} 1.0 \mathrm{M}$ vanadium electrolyte (Oxkem, Reading, UK) on each side, $40 \mathrm{~mL} \mathrm{~min}{ }^{-1}$ flow rate, $25 \mathrm{~cm}^{2}$ cell area and cut-off voltages of $1.65 \mathrm{~V}$ and $0.8 \mathrm{~V}$ for the charge and discharge, respectively. After cycling, the electrolyte and the carbon felt electrode were renewed stepwise in order to determine their contribution to the total capacity loss. 
membranes due to lower and more balanced transport of vanadium across the membrane. As presented in Figure 6 , at $160 \mathrm{~mA} / \mathrm{cm}^{2}$ a net vanadium flux is observed towards the positive side for all membranes tested. In the case of NR212, 50\% of the initial discharge capacity was lost after 13 charge-discharge cycles, which is faster compared to previous literature (Jiang et al observe $50 \%$ capacity loss after 40 cycles at $80 \mathrm{~mA} \mathrm{~cm}^{-2}$, [36] $\mathrm{Xi}$ et al observe $50 \%$ capacity loss after 300 cycles at $80 \mathrm{~mA} \mathrm{~cm}^{-2}$ [37]). This difference can be largely explained with the enhancing effect of the current density on the net vanadium permeation towards the positive side. This permeation is however significantly reduced by more than $60 \%$ in the case of a $4 \mu \mathrm{m}$ layer of $\mathrm{PBI}$ and the discharge capacity was almost completely regenerated after exchanging the carbon felt electrodes (Figure 7). The fixed positive charges introduced with the PBI layer successfully counteract the net migrative flux in a vanadium flow battery. The amount of positive charges needs to be adjusted to the current density range, which can be derived from the results presented in Figure 6 .

\section{Conclusions}

Bilayer PBI/Nafion ${ }^{\circledR}$ membranes were prepared with defined content of cation and anion exchange groups by varying the thickness of the PBI layer. The fixed positive charges in the membrane introduced with protonated PBI provide an effective barrier towards vanadium ions, reducing the rate of vanadium crossover and improving the coulombic efficiency. Here we utilized the content of fixed positive charges to counteract net migrative vanadium flux resulting from the different charged ions present in the positive and negative electrolyte. Both, coulombic repulsion from the membrane and the migrative flux across the membrane are linearly depending on the effective charge of the dissolved vanadium ion. Thus, the content of fixed positive charges must be correlated to the current density in order to balance transport processes. The performance of a vanadium flow battery was increased and the capacity fading reduced compared to a pristine Nafion $®$ membrane even at $160 \mathrm{~mA} \mathrm{~cm}^{-2}$. For a current density of $120 \mathrm{~mA} \mathrm{~cm}^{-2}$, a PBI thickness between 3$4 \mu \mathrm{m}$ completely balances vanadium transport and hence suppresses net vanadium flux. The present work may guide vanadium flow battery manufacturers to choose the membrane according to their specific range of expected current densities, in order to avoid cost intense electrolyte remixing and to reduce the levelized cost of storage of their systems.

\section{Experimental Section}

\section{Preparation of bilayer Nafion $₫ / P B I$ membranes}

Bilayered Nafion $₫ /$ meta-polybenzimidazole (PBI) membranes were prepared by hot-pressing a PBI- and a Nafion $₫$ NR212-film onto each other at $80^{\circ} \mathrm{C}$ for $3 \mathrm{~min}$. Nafion ${ }^{\circledR} \mathrm{NR} 212$ was used as received, $\mathrm{PBI}$ films were prepared in defined thickness by casting a $10 \mathrm{w} \%$ solution of $\mathrm{mPBI}$ in dimethylacetamide onto a glass plate. The cast film was dried at $110^{\circ} \mathrm{C}$ for $5 \mathrm{~min}$ and subsequently cured at $150^{\circ} \mathrm{C}$ for $10 \mathrm{~min}$. The Nafion $囚 / P B I$ bilayer membranes were immersed for $8 \mathrm{~h}$ in the acidic electrolyte in order to form the imidazolium moiety.

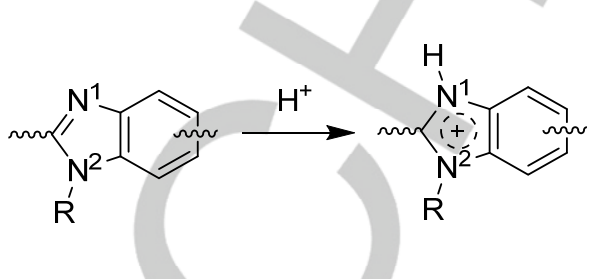

Cross-sectional analysis with SEM and EDX

The cross-section was analyzed using scanning electron microscopy coupled with energy dispersive X-ray spectroscopy (SEM/EDX). For this, membranes were frozen in liquid nitrogen and broken to obtain a sharp cross-section. The SEM image was taken using a FESEM Ultra 55 from Carl Zeiss with an acceleration voltage of $5 \mathrm{kev}$, a magnification of 1700 and a working distance of $7.2 \mathrm{~mm}$. Energy dispersive X-ray analysis was performed using a compatible accessory (EDAX TSL, AMETEK).

Theoretical and experimental ion exchange capacity

To determine the theoretical ion exchange capacity of bilayered Nafion®/PBI membranes, the cation exchange capacity (CEC) and anion exchange capacity (AEC) of NR212 and PBI, respectively, was determined separately. The cation and anion exchange capacity was determined using the mass share of NR212 and PBI in the bilayered membrane according to:

$$
\begin{gathered}
C E C^{\text {theo }}(\text { bilayer })=\frac{m(N R 212)}{m(N R 212)+m(P B I)} \cdot C E C(N R 212) \\
A E C^{\text {theo }}(\text { bilayer })=\frac{m(P B I)}{m(N R 212)+m(P B I)} \cdot A E C(P B I)
\end{gathered}
$$

with the ion exchange capacity given in $\mathrm{mmol} \mathrm{g}^{-1}$ and the mass $m$ in $\mathrm{g}$. For the pristine NR212 and $\mathrm{PBI}$, a cation exchange capacity of $0.94 \pm 0.02 \mathrm{mmol} \mathrm{g}^{-1}$ and an anion exchange capacity of $3.2 \pm 0.1 \mathrm{mmol} \mathrm{g}^{-1}$ were determined, respectively. The theoretical ion exchange capacity of the bilayered membrane would be identical to the experimental values if no ion exchange capacity is lost due to interionic crosslinking or shielding. The experimental ion exchange capacity was determined with titration. For that, all membranes were fully protonated in $2 \mathrm{M} \mathrm{H}_{2} \mathrm{SO}_{4}$ overnight and subsequently washed with water, until a neutral $\mathrm{pH}$ was observed. Afterwards, the fully protonated membrane samples were immersed in $1 \mathrm{M}$ $\mathrm{KCl}$ solution in order to exchange the acidic protons (corresponding to the sulfonic acid groups of NR212). The cation exchange capacity was determined from direct titration of the exchanged protons with $0.05 \mathrm{M} \mathrm{KOH}$ and calculated according to:

$$
C E C^{\text {exp }}(\text { bilayer })=\frac{c\left(m m o l ~ L^{-1}\right) \cdot f \cdot V(L)}{m_{d r y}(g)}
$$

To determine the anion exchange capacity, the samples were removed from the $\mathrm{KCl}$-solution and again washed with water until a neutral $\mathrm{pH}$ was 
observed. Titration was then performed indirectly by adding $2 \mathrm{~mL} \mathrm{KOH}$ $\left(0.05 \mathrm{~mol} \mathrm{~L}^{-1}\right)$ to the samples. After $2 \mathrm{~h}$, this solution was titrated with $0.05 \mathrm{M} \mathrm{HCl}$ and the anion exchange capacity was calculated according to:

$$
A E C^{\text {exp }}(\text { bilayer })=\frac{\left[c^{\mathrm{KOH}} \cdot f^{\mathrm{KOH}} \cdot V^{\mathrm{KOH}}\right]-\left[c^{\mathrm{HCl}} \cdot f^{\mathrm{HCl}} \cdot V^{\mathrm{HCl}}\right]}{m_{\text {dry }}(g)}
$$

including the concentration $c\left(\mathrm{mmol} \mathrm{L}^{-1}\right)$, the titration factor $f$ and the volume $V(L)$ of the titration solution.

\section{Cell tests}

All in situ tests were performed with a Scribner Model 857 test stand (Scribner Associates) using a $1.6 \mathrm{M}$ vanadium electrolyte at room temperature (Oxkem, Reading UK), a flow-by set-up with a triple serpentine flow field, pretreated SGL GFD4.6EA carbon felt electrodes $\left(400^{\circ} \mathrm{C}, 30 \mathrm{~h}, 30 \%\right.$ compression) and a flow-rate of $40 \mathrm{~mL} \mathrm{~min}^{-1}$. In all experiments including bilayer $\mathrm{PBI} / \mathrm{Nafion} \circledast$ membranes, the $\mathrm{PBI}$ side was facing the positive half-cell. The through-plane area resistance was determined using electrochemical impedance spectroscopy at a state-of charge of $-50 \%$. Impedance spectra were recorded between $100 \mathrm{kHz}$ and $1 \mathrm{mHz}$ at $0 \mathrm{~V}$ open circuit potential with a voltage amplitude of $100 \mathrm{mV}$. The ohmic area resistance was obtained from the high frequency resistance (HFR) of the spectra and the cell area according to:

$$
R_{\text {ohmic }}=\operatorname{HFR}(\Omega) \cdot 25 \mathrm{~cm}^{2}
$$

\section{Ex situ vanadium flux}

The ex situ vanadium flux describes the expected vanadium flux in a cell where V(II) and V(III) are present in the negative electrolyte and V(IV) and $\mathrm{V}(\mathrm{V})$ are present in the positive electrolyte all at the same concentration and with diffusion being the only transport mode. The net vanadium flux is calculated according to:

$$
\begin{aligned}
& \sum \text { Diffusivity (negative electrolyte) } \\
& \qquad-\sum \text { Diffusivity (positive electrolyte) }
\end{aligned}
$$

A negative net flux represents transport towards the negative side and results from higher diffusivity of vanadium species present in the positive side. The diffusivity of each ion was determined separately using selfmade diffusion cells consisting of a vanadium donating chamber and a receiving chamber with $1 \mathrm{MV}(\mathrm{x})$ in $2 \mathrm{M} \mathrm{H}_{2} \mathrm{SO}_{4}$ and $1 \mathrm{M} \mathrm{MgSO}_{4}$ in $2 \mathrm{M}$ $\mathrm{H}_{2} \mathrm{SO}_{4}$, respectively. The vanadium concentration in the receiving chamber was determined over time with UV/vis-spectroscopy to calculate the diffusivity as reported in previous literature. $\left[{ }^{[38]}\right]$

\section{In situ vanadium flux}

The in situ vanadium flux is the net flux of vanadium between the negative and the positive electrolyte determined from the vanadium concentration and the volume of the fully discharged electrolyte over 50 cycles. For all measurements, the first 20 cycles were used for conditioning and neglected in the analysis. In this region the vanadium transport is superimposed by electrolyte flux resulting from an osmotic pressure gradient formed during the initial charging reaction (when using vanadium electrolyte with an average charge of the ions of $3.5(-50 \%$ state of charge) a proton gradient forms during the first charging that is not fully reversed during discharge). Again a negative flux represents transport towards the negative electrolyte. To measure the concentration, $300 \mu \mathrm{L}$ samples were taken periodically over time once the applied potential was close to the lower termination voltage $(0.8 \mathrm{~V})$, corresponding to a state of charge of 0 $5 \%$. The sample was divided in 3 aliquots and a redox titration with $\mathrm{KMnO}_{4}$ in $2 \mathrm{M} \mathrm{H}_{2} \mathrm{SO}_{2}$ was performed. The net vanadium flux can be calculated using the vanadium concentration $c\left(\mu \mathrm{mol} \mathrm{L}^{-1}\right)$, the volume $V(\mathrm{~L})$, the operating time $t(\mathrm{~h})$ and the cell area $A_{\text {cell }}\left(\mathrm{cm}^{2}\right)$ :

$$
\frac{\left[c_{\text {pos }} \cdot V_{\text {pos }}\right]-\left[c_{\text {neg }} \cdot V_{\text {neg }}\right]}{t \cdot A_{\text {cell }}}
$$

The total volume of the electrolyte was gradually decreasing due to the continuous argon purging of the two electrolyte compartments and evaporation.

\section{Acknowledgements}

We acknowledge the Swiss Federal Office of Energy (SFOE) for their financial support within the RFBmem project (Grant No. SI/501421-01). TJS thanks CTI and the Swiss Competence Center for Energy Research (SCCER) Heat \& Electricity Storage.

Keywords: vanadium redox flow batteries $\cdot$ amphoteric membranes $\bullet$ capacity fading $\bullet$ electrolyte transport • polybenzimidazole

[1] O. Schmidt, A. Hawkes, A. Gambhir, I. Staffell, Nat. Energy 2017, 6, 17110.

[2] International Renewable Energy Agency, Renewable Energy Statistics 2017.

[3] C. Minke, T. Turek, J. Power Sources 2018, 376, 66-81.

[4] A. Tang, J. Bao, M. Skyllas-Kazacos, J. Power Sources 2011, 196, 10737-10747.

[5] Y. Zhang, L. Liu, J. Xi, Z. Wu, X. Qiu, Appl. Energy 2017, 204, 373-381.

[6] S. Corcuera, M. Skyllas-Kazacos, Eur. Chem. Bull. 2012, 1, 511-519.

[7] S. Rudolph, U. Schroeder, I. M. Bayanov, J. Electroanal. Chem. 2013, 703, 29-37.

[8] M. A. Aziz, S. Shanmugam, J. Mater. Chem. A 2018, 6, 17740-17750.

[9] L. Yu, F. Lin, W. Xiao, L. Xu, J. Xi, Chem. Eng. J. 2019, 356, 622-631.

[10] J. B. Liao, M. Z. Lu, Y. Q. Chu, J. L. Wang, J. Power Sources 2015, 282, 241-247.

[11] M. A. Aziz, S. Shanmugam, J. Mater. Chem. A 2017, 5, 16663-16671.

[12] B. Bauer, T. Klicpera, K. Reinwald, M. Schuster, Electrolyte Management at VRFB Using Anion-Exchange-Membranes; Ion Exchange Membranes for Energy Applications, Bad Zwischenahn, 2018.

[13] C. Sun, J. Chen, H. Zhang, X. Han, Q. Luo, J. Power Sources 2010, 195, 890-897.

[14] Q. Luo, L. Li, Z. Nie, W. Wang, X. Wei, B. Li, B. Chen, Z. Yang, J. Power 
Sources 2012, 218, 15-20.

[15] Y. Ashraf Gandomi, D. S. Aaron, M. M. Mench, Electrochim. Acta 2016, 218, 174-190.

[16] R. M. Darling, A. Z. Weber, M. C. Tucker, M. L. Perry, J. Electrochem. Soc. 2015, 163, A5014-A5022.

[17] J. H. Park, J. J. Park, O. O. Park, J. H. Yang, ChemSusChem 2016, 3181-3187.

[18] D. Mu, Y. Zhao, L. Yu, L. Liu, J. Xi, Phys. Chem. Chem. Phys. 2017, 19, 29195-29203.

[19] E. Agar, A. Benjamin, C. R. Dennison, D. Chen, M. A. Hickner, E. Caglan, 224th ECS Meet. Abstr. 2013, 196, 2013.

[20] K. Wang, L. Liu, J. Xi, Z. Wu, X. Qiu, J. Power Sources 2017, 338, 17-25.

[21] B. Li, Q. Luo, X. Wei, Z. Nie, E. Thomsen, B. Chen, V. Sprenkle, W. Wang, ChemsusChem 2014, 7, 577-584.

[22] L. Yan, D. Li, S. Li, Z. Xu, J. Dong, W. Jing, W. Xing, ACS Appl. Mater. Interfaces 2016, 8, 35289-35297.

[23] F. J. Oldenburg, T. J. Schmidt, L. Gubler, J. Power Sources 2017, 368, 68-72.

[24] T. Luo, O. David, Y. Gendel, M. Wessling, J. Power Sources 2016, 312, 45-54.

[25] Z. Yuan, Y. Duan, H. Zhang, X. Li, H. Zhang, I. Vankelecom, Energy Environ. Sci. 2016, 9, 441-447.

[26] S. Maurya, S.-H. Shin, J.-Y. Lee, Y. Kim, S.-H. Moon, RSC Adv. 2016, 6, 5198-5204.

[27] X. L. Zhou, T. S. Zhao, L. An, L. Wei, C. Zhang, Electrochim. Acta 2015, 153, 492-498.

[28] M. Jung, W. Lee, N. Nambi Krishnan, S. Kim, G. Gupta, L. Komsiyska, C. Harms, Y. Kwon, D. Henkensmeier, Appl. Surf. Sci. 2018, 450, 301-311.

[29] S. M. Ahn, H. Y. Jeong, J. K. Jang, J. Y. Lee, S. So, Y. J. Kim, Y. T. Hong, T. H. Kim, RSC Adv. 2018, 8, 25304-25312.

[30] O. Nibel, T. Rojek, T. J. Schmidt, L. Gubler, ChemSusChem 2017, 10, 2767-2777.

[31] S. Gupta, T. M. Lim, S. H. Mushrif, Electrochim. Acta 2018, 270, 471-479.

[32] F. J. Oldenburg, M. Bon, D. Perego, D. Polino, T. Laino, L. Gubler, T. J. Schmidt, Phys. Chem. Chem. Phys. 2018, 20, 23664-23673.

[33] K. W. Knehr, E. Agar, C. R. Dennison, A. R. Kalidindi, E. C. Kumbur, J. Electrochem. Soc. 2012, 159, A1446-A1459.

[34] A. H. Whitehead, M. Harrer, J. Power Sources 2013, 230, 271-276.

[35] O. Nibel, S. M. Taylor, A. Pătru, E. Fabbri, L. Gubler, T. J. Schmidt, J. Electrochem. Soc. 2017, 164, A1608-A1615.

[36] B. Jiang, L. Wu, L. Yu, X. Qiu, J. Xi, J. Memb. Sci. 2016, 510, 18-26.

[37] J. Xi, B. Jiang, L. Yu, L. Liu, J. Memb. Sci. 2017, 522, 45-55.

[38] Z. Mai, H. Zhang, X. Li, C. Bi, H. Dai, J. Power Sources 2011, 196, 482 487. 
WILEY-VCH

\section{Entry for the Table of Contents}

\section{FULL PAPER}

The net transport of vanadium from the negative to the positive electrolyte through the ion-exchange membrane of a vanadium flow battery during charge/discharge cycling can be tuned by using amphoteric PBI/Nafion® bilayer membranes. Thus, the capacity fading of the battery can be minimized.

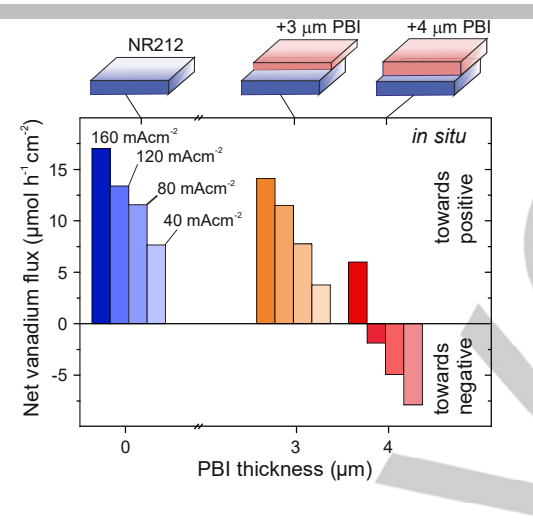

F. J. Oldenburg, E. Nilsson, T.J. Schmidt, L. Gubler*

Page No. - Page No.

Tackling Capacity Fading in Vanadium Redox Flow Batteries with Amphoteric PBI/Nafion Bilayer Membranes 


\section{Supplementary Information}

\section{Tackling Capacity Fading in Vanadium Redox-Flow Batteries with Amphoteric $\mathrm{PBI} /$ Nafion Bilayer Membranes}

Fabio Jonas Oldenburg, ${ }^{a}$ Elisabeth Nilsson, ${ }^{a}$ Thomas Justus Schmidt ${ }^{\mathrm{a}, \mathrm{b}}$ and Lorenz Gubler ${ }^{\mathrm{a}}$

a. Electrochemistry Laboratory, Paul Scherrer Institut, 5232 Villigen PSI, Switzerland.

b. Laboratory of Physical Chemistry, ETH Zürich, 8093 Zurich, Switzerland.

Content

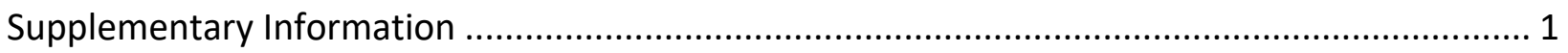

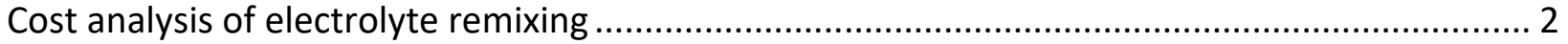

The cost estimate was performed for a $1 \mathrm{MW} / 6 \mathrm{MWh}$ battery with the following

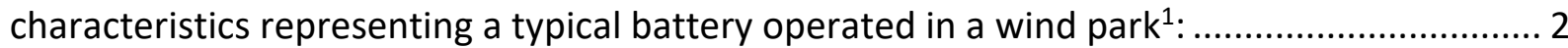

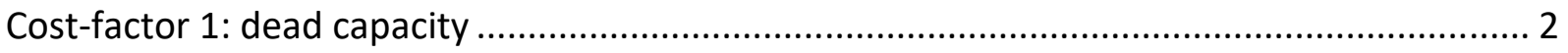

Cost-factor 2: energy lost in rebalancing ........................................................................ 2

Electrode degradation study with electrochemical impedance spectroscopy ....................... 2

Delamination of PBI/Nafion ${ }^{\circledR}$ bilayer after cycling ............................................................ 3

Equilibration effects during the initial charging .............................................................. 4

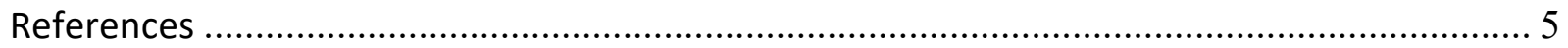




\section{Cost analysis of electrolyte remixing}

The cost estimate was performed for a $1 \mathrm{MW} / 6 \mathrm{MWh}$ battery with the following characteristics representing a typical battery operated in a wind park ${ }^{1}$ :

\begin{tabular}{lrll} 
Lifetime & 20 & years \\
\hline Cycle life & 10000 & Cycles \\
\hline Energy stored over lifetime & 43.8 & GWh & \\
\hline Electrolyte cost & 114 & $\$ / \mathrm{kWh}$ & 2 \\
\hline Power & 1 & $\mathrm{MW}$ & \\
\hline Energy & 6 & $\mathrm{MWh}$ & \\
\hline Discharge t & 4 & $\mathrm{Hrs}$ \\
\hline Cycles per day & 1 & & \\
\hline min SOC & 0 & $\%$ & \\
\hline max SOC & 100 & $\%$ & 3 \\
\hline Capacity fading & 1.8 & $\% / c y c l e$ & 3 \\
\hline Rebalancing at & 60 & $\%$ of initial SOC & 3 \\
\hline LCOE wind & 0.17 & \$/kWh &
\end{tabular}

\section{Cost-factor 1: dead capacity}

Due to the linear capacity fading of the vanadium flow battery between $100 \%$ and $60 \%$ discharge capacity, the average capacity of the system is $80 \%$ (representing $4.8 \mathrm{MWh}$ ). If $6 \mathrm{MWh}$ are required, this necessitates an extra investment of $1.5 \mathrm{MWh}$ electrolyte corresponding to $170 \mathrm{k} \$\left(3.9 \$ \mathrm{MWh}^{-1}\right)$.

\section{Cost-factor 2: energy lost in rebalancing}

Imbalanced electrolyte transport is fully reversible by complete mixing of both electrolyte compartments. To minimize the energy lost in this process, the remixing is performed in the discharged state (at $10 \%$ state of charge). After remixing, both electrolyte compartments contain equal amounts of $\mathrm{V}(\mathrm{III})$ and $\mathrm{V}(\mathrm{IV})$ corresponding to a state of charge of $-50 \%$. The initial charging consequently requires charging the electrolyte from $-50 \%$ to $100 \%$. Upon remixing, $60 \%$ of the capacity (3.6 MWh) are lost, corresponding to $612 \$$ rebalancing ${ }^{-1}\left(4.25 \$ \mathrm{MWh}^{-1}\right)$.

\section{Electrode degradation study with electrochemical impedance spectroscopy}

The area resistance was observed to be stable even after extended cycling experiments indicating the stability of membranes used. However the charge-transfer resistance obtained from the low-frequency resistance significantly increases after extended cycling experiments and could only be regenerated by exchanging the electrode felts (cf. Figure S1). The decreasing performance can thus be related to the limited stability of carbon felt electrodes used the negative side. 


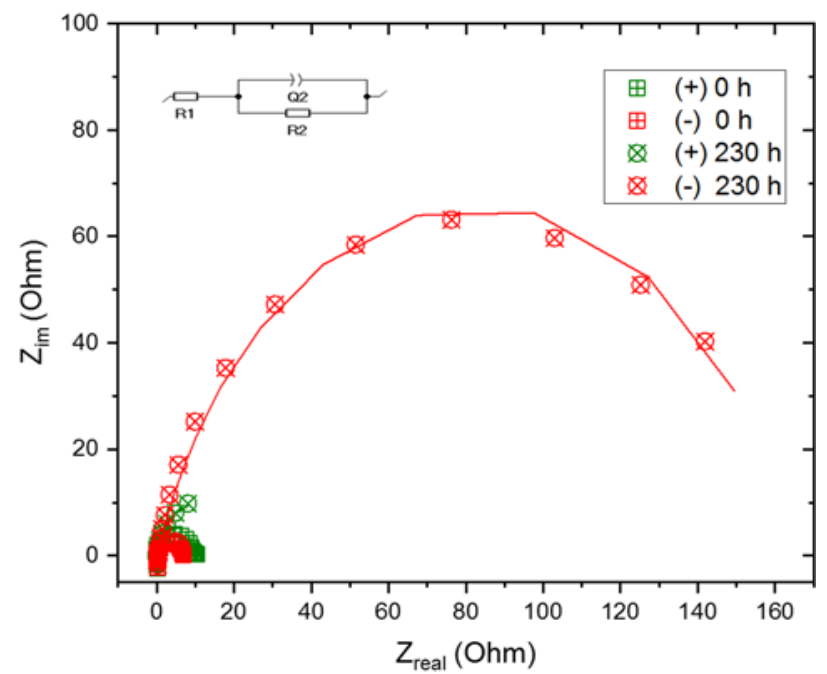

Figure S1. Electrochemical impedance spectra of a cell assembled with heat-treated GFD4.6EA electrodes (SGL) and 1.6 M vanadium in $2 \mathrm{M} \mathrm{H}_{2} \mathrm{SO}_{4}$ electrolyte (Oxkem, Reading). The spectra were measured between two half-cells and were characterized separately against a reference electrode (edge-type assembled reference electrode $\left(\mathrm{Hg} / \mathrm{Hg}_{2} \mathrm{SO}_{4}, \mathrm{C}_{3}\right.$ Prozess- und Analysetechnik). ${ }^{5}$

\section{Analysis of $\mathrm{PBI} /$ Nafion $^{\circledast}$ bilayer after cycling}

After 50 charge-discharge cycles, all PBI/Nafion ${ }^{\circledR}$ bilayer membranes were still fully intact and no delamination of the layers was observed (Figure S2, left). This is related to the interionic acid-base bonds between the Nafion ${ }^{\circledR}$ and the PBI ionomers and the compression of the cell during the cycling experiments. However a more detailed analysis of the membrane cross-section using SEM/EDX-microscopy revealed a gap of around 1-2 $\mu \mathrm{m}$ at the interface. This could be related to the sample preparation for SEM analysis. Long-term stability in the cell needs further study.

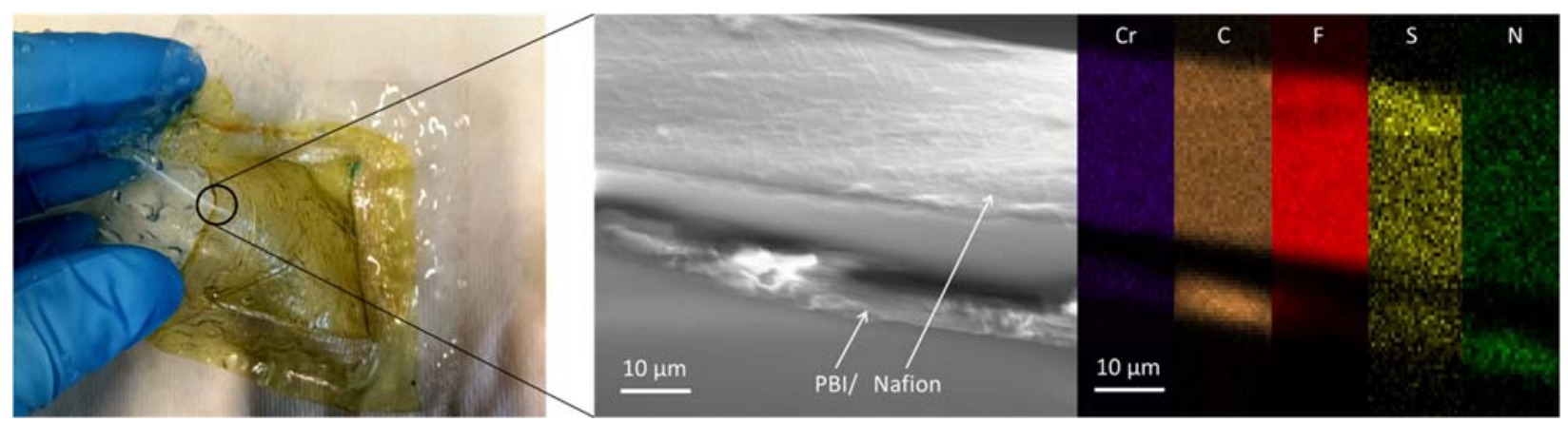

Figure S2. Left: $\mathrm{PBI} /$ Nafion $^{\circledR}$ bilayer membrane after 50 charge-discharge cycles. Right: Cross-sectional analysis of a PBI/Nafion bilayer membrane with a PBI thickness of $4 \mu \mathrm{m}$ after cycling for 50 charge-discharge cycles. in gray: SEM image; in colour: EDX elemental mapping of nitrogen (green), chromium (purple) (= sputter coated element), carbon (brown), sulphur (yellow) and fluorine (red). 


\section{Equilibration effects during the initial charging}

A strong volume imbalance was observed after the first charging reaction (Figure S3, bottom). This volume imbalance results from water transport across the membrane due to a strong proton gradient that is formed during the initial charging reaction (from $-50 \%$ to $100 \%$ state of charge). Especially in the case of anion exchange membranes the additional protons present in the positive electrolyte cannot be directly balanced and cause an initial volume imbalance. This means that electrolyte transport processes can only be analyzed accurately when considering the actual vanadium content. If only volumes are considered, extended cycling is necessary to gain qualitative information.
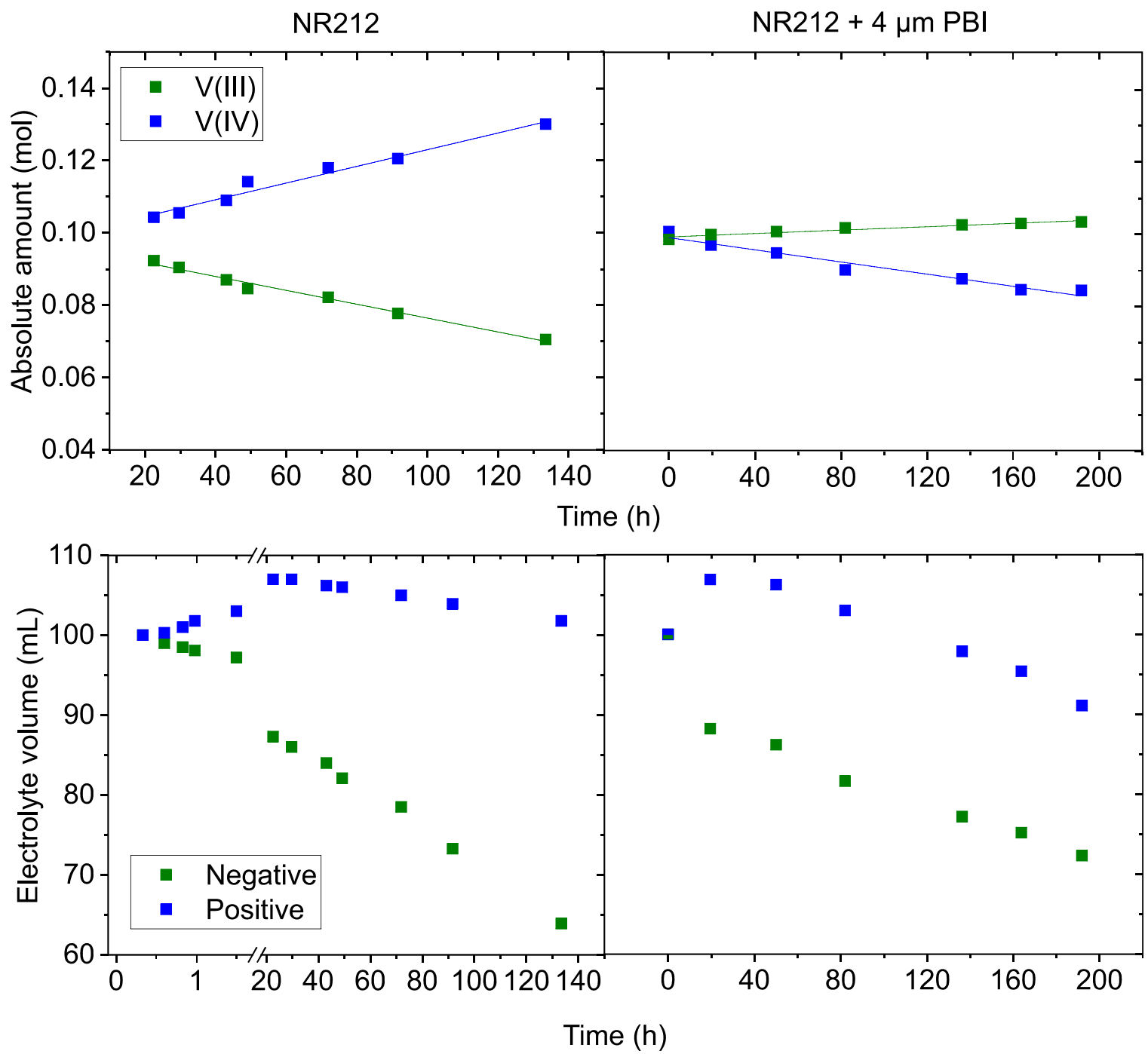

Figure S3. Top: absolute amount of vanadium present in the fully discharged negative and positive electrolyte of a cell assembled with Nafion ${ }^{\circledR}$ NR212 (left) and a bilayered Nafion ${ }^{\circledR}$ NR212/PBI membrane (right). Samples were taken over time at 0\% state of charge. The cell was operated at a constant current density of $80 \mathrm{~mA} \mathrm{~cm}$ (voltage range between 0.8-1.65 V) with $1 \mathrm{M}$ vanadium in $2 \mathrm{M} \mathrm{H}_{2} \mathrm{SO}_{4}$ (Oxkem, Reading, UK) and heat-treated carbon felt electrodes (SGL GFD4.6EA). Bottom: Positive and negative electrolyte volume of the same cell determined at $0 \%$ state of charge (except for the first $2 \mathrm{~h}$ representing the initial charge process). The absolute amount of vanadium was calculated from the observed volume and the concentration determined with redox-titration. 


\section{References}

(1) Zhao, H.; Wu, Q.; Hu, S.; Xu, H.; Rasmussen, C. N. Review of Energy Storage System for Wind Power Integration Support. Appl. Energy 2015, 137, 545-553.

(2) Minke, C.; Turek, T. Materials, System Designs and Modelling Approaches in Techno-Economic Assessment of AllVanadium Redox Flow Batteries - A Review. J. Power Sources 2018, 376, 66-81.

(3) Bauer, Bernd; Klicpera, Tomas; Reinwald, Karsten; Schuster, M. Electrolyte Management at VRFB Using Anion-ExchangeMembranes, Ion Exchange Membranes for Energy Applications (EMEA), Bad Zwischenahn, Germany, June 26-28, 2018. (http://emea-workshop.de/emea-workshop-2018)

(4) Stehly, T.; Heimiller, D.; Scott, G. National Renewable Energy Laboratory (NREL): 2016 Cost of Wind Energy Review. 2016.

(5) Nibel, O.; Taylor, S. M.; Pătru, A.; Fabbri, E.; Gubler, L.; Schmidt, T. J. Performance of Different Carbon Electrode Materials: Insights into Stability and Degradation under Real Vanadium Redox Flow Battery Operating Conditions. J. Electrochem. Soc. 2017, 164, A1608-A1615. 